\title{
OSTEOLOGY OF THE CAUDAL FIN OF SOME SPECIES OF CICHLIDAE (PISCES, PERCIFORMES, LABROIDEI)
}

\author{
A.S.C. Sebilia ${ }^{1}$ \\ J.V. Andreata ${ }^{1}$
}

\begin{abstract}
This paper concerns the dejinition of the caudal fin of nine species of Cichilidae. For this, the caudal fin was analyzed regarding shape and position of the urostyle, parahypural and haemal spine 2 as well as the degree of ossification of the hypuraphophysis, number of caudal rays and distribution on their supporting elements.

\section{INTRODUCTION}

The family Cichlidae is distributed over the tropical and subtropical regions of America and Africa and represents $6 \%$ of the continental icthyofaune of South America (Lowe-McConnell, 1975). Its geographic distribution is regulated by low temperatures (Kullander, 1981) as shown by fossil records (Pellegrin, 1903). Very little taxonomic work has been undertaken in Brazil, where the native species are in need of more accurate studies for a better definition of the species and genera. This paper ains to analyze the caudal fin of some species of the brazilian cichlids, using as well two african species which where indiscriminately introduced in our natural brazilian habitats, in order to show the importance of the use of this structure in defining characteristics of the group.
\end{abstract}

\section{MATERIAL AND METHODS}

The following species were examined: Tilapia rendalli (Boulenger, 1898); Oreochromis niloticus (Linnaeus, 1758) introduced in Brazil in 1953 from the Congo; $\mathrm{Ci}$ chla ocellaris (Bloch \& Scheneider, 1801); Astronotus ocellatus (Swainson, 1839); Gymnogeophz\&us rhabdotus (Hensel, 1870); Cichlasoma portalegrense (Hensel, 1870); Cichlasoma facetum (Jenyns, 1842); Geophagus brasiliensis (Quoy \& Gaimard, 1824) and Crenicichla lacustris (Castelnau, 1855).

This studied material was collected in Mangueira Lagoon, Basin of Jacui River, Osório and Tramandaí Streams, Rio Grande do Sul State; Guarapiranga Dam, São Paulo State; Areal, Petrópolis and Vassouras Streams, Tijuca and Marapendi lagoons, Rio de Janeiro State; Iconha River, Espirito Santo State and Paranoá Lake, Brasilia, Federal District, and was obtained during surveys made by the Laboratory of Ichthyology of Santa Úrsula University in the central-west, southeast and south of the brazilian territory. Two hundred and thirty specimens where prepared in accordance with Davis and

1. Dept? Biologia Animal, Universidade Santa Úrsula, Rua Fernando Ferrari, 75, CEP 22231, Rio de Janeiro, Brasil. 
Gore (1936) method and the osteological nomenclature of Monod (1968) and adapted by Andreata (1979). The drawings were executed with a Stereomicroscope Wild M-3 with drawing attachment. The material is deposited in the ichthyological collection of Santa Ürsula University, Rio de Janeiro.

Abreviations used in figures and in text:

CP 1-3: preural centrum 1-3

CU 1-2: ural centrum 1-2

E 1-2: epurals $1-2$

HI-V: hypurals I-V

HEM 2 and 3: Haemal spine 2 and 3

NEU 3: neural spine 3

$\mathrm{PH}$ : parahypural

PP: hypuraphophysis

RA: acessory (procurrent) caudal rays

$\mathrm{RC}$ : caudal rays (total number)

RP: principal caudal rays

BR: branched caudal rays

ST: stegural

UN: uroneural

UR: urostyle

\section{RESULTS}

Caudal fin of the Cichlidae - general plan (Fig. 1).

Five vertebrae support the caudal fin: three pre-ural (CP1, CP2 and CP3) and two ural central (CUI and CUII). The pre-ural centraum 1 (CPI) is fused to the ural centrum I and II forming a complex centrum CPI + CUI + CUII - urostyle -, normally of a conical shape with a distal region pointed (Figs. 2, 3, 5, 6) or not pointed (reduced) (Figs. 4, 7, 8, 9, 10).

The pre-ural centrum 3 has a neural spine and a long and thin haemal spine which may or may not support the anterior most procurrent caudal rays.

The pre-ural centrum 2 has a reduced neural spine turned toward the epurals, and presenting itself as a complement to the base of the epural 1 , like pieces of a puzzle.

According to Patterson (1968) the pre-ural centrum 2 in the most primitive forms, shows a fully developed neural spine supporting epaxial rays (Polimixioidei) or a reduction may occur (Dinopterigoidei). In the more advanced forms of Berycoidei and Perdoidei, this reduction causes a small spine to appear. In ancestral Teleostei, the Pholidophorids, the neural spines of the three last pre-ural vertebrae decrease progressively in size, ending on aproximately the same oblique plan. In the various forms in which the pre-ural centrum 2 does not present a fully developed neural spine, but a rudimentary one, this detached spine will appear as an epural, producing the typical condition of the Percoidei. On the other hand, in various groups of Perciforms and derivatives, the epural $1 \mathrm{can}$ blend itself to the neural arc, indicating that these structures are originally a part of the same segment, as found in the Polimixioidei (Patterson, 1968). In the space between the neural spine 3 and the hypural V, two epurals of different sizes are present, epural 1 being larger than epural 2 .

Resting dorsally on the urostyle (UR) and the hypural V, a long and pointed stegural (ES). Resting ventrally on the urostyle, there is a parahypural (PH) structurally 
Vol. 7(3), 1990

similar to the haemal spine 2. A progressive enlargement of the base towards the distal region may occur (Figs. 3, 5,6) or an alternativelly progressive enlargemnt with a little strangulation towards the medium distal region (Figs. 2, 4, 7-10). This parahy pural leads a hypuraphophysis (PP), small reduced, not belonging the hypural I (Figs. 2, 6, 10); expanded and belonging the hypural I (Figs. 3, 4, 5) or belonging the hypural II (Figs. $7,8,9$ ), serving for insertion of the hypocordal longitudinalis muscles. Five autogenous hypurals can be counted: the fifth hypural, the smallest of there, is completely individualized. The fourth hypural, of a laminar aspect, is firmly fitted into the urostyle and resting, or not, on the third hypural. Between the third and the second hypurals there is a diastema (D) of a triangular aspect. The first hypural keeps the same proportions as the fourth and does not show any process of fusion to the parahypural or the second hypural. Sixteen branched - segmented caudal rays (RP) can be counted: eight of them forming the upper lobe (epaxial) and eight forming the lower lobe (hipaxial). In addition, fourteen rays are segmented and branched and two are only segmented. The number of the accessory caudal rays (RA) varied from six to eighteen among the species.

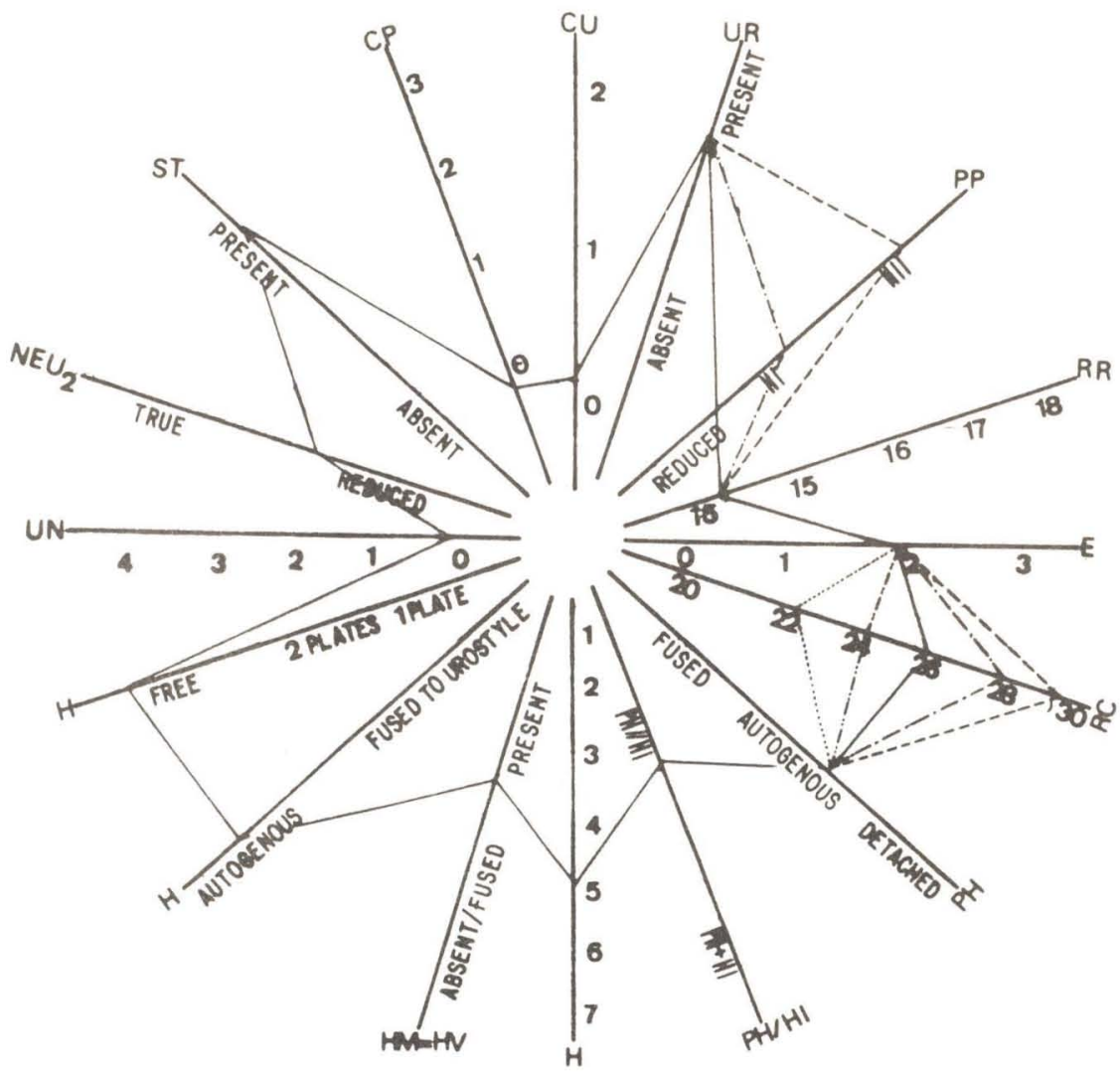

Fig. 1 - Grafic representation of the urophore complex and their variation (modified from.Monod, 1968). 
Revta bras. Zool.

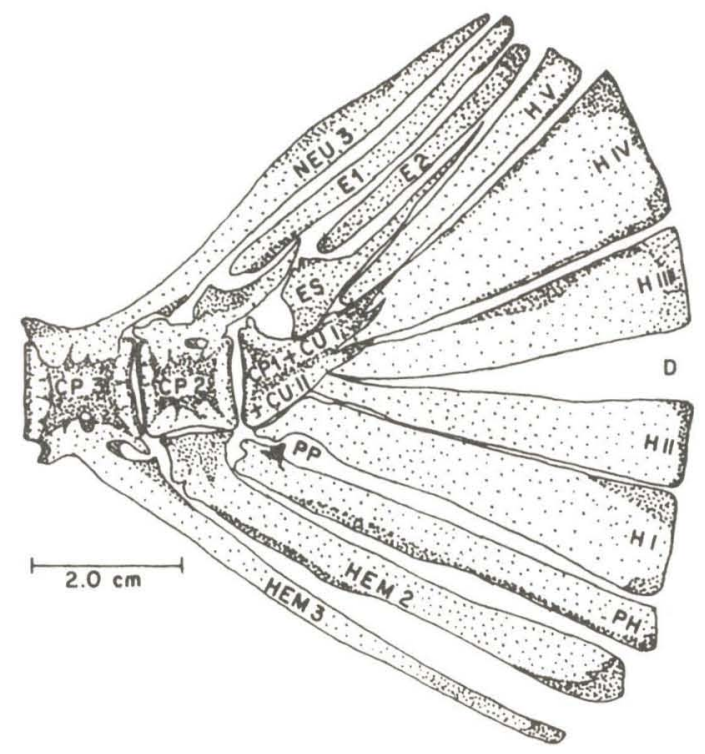

Fig. 2 - The urophore complex of Cichlasoma portalegrense (Hensel, 1870), lateral view.

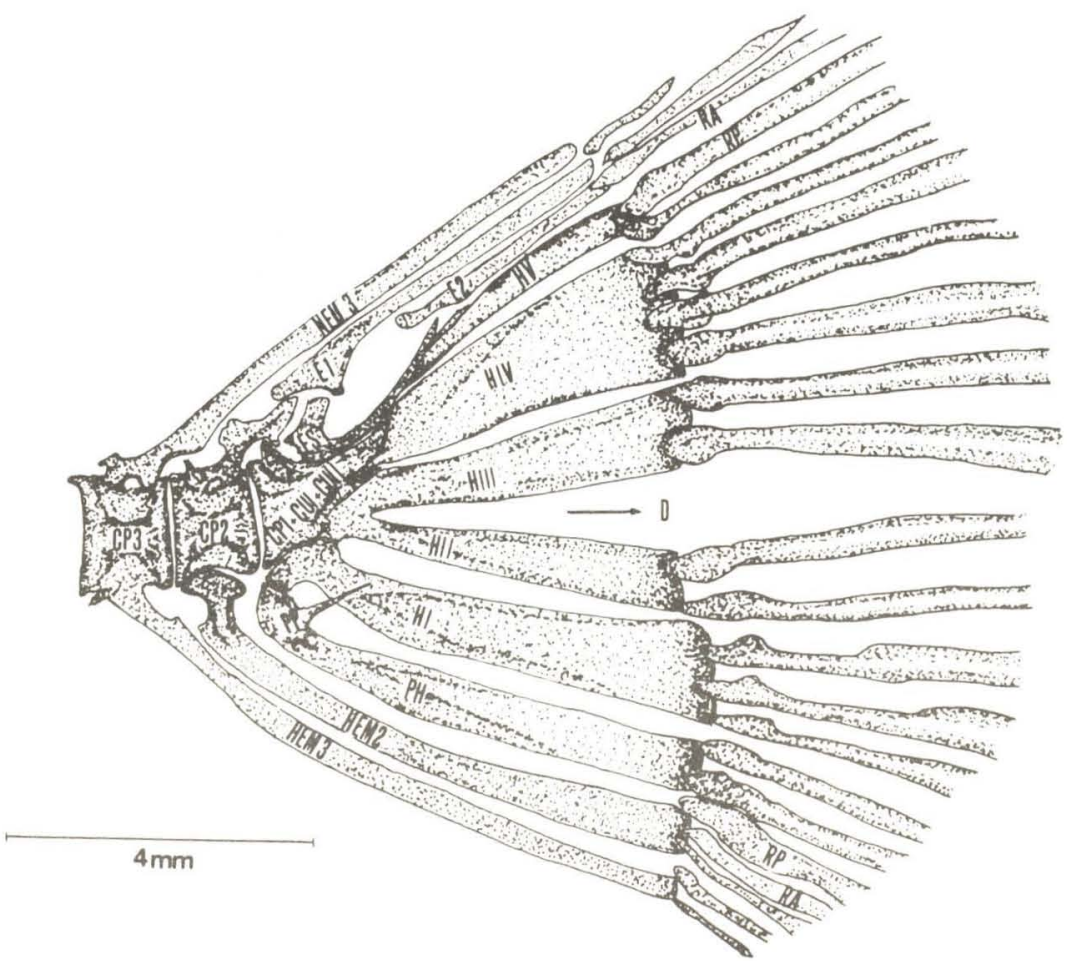

Fig. 3 - The urophore complex of Cichlasoma facetum (Jennyns, 1842), lateral view. 
Vol. 7(3), 1990

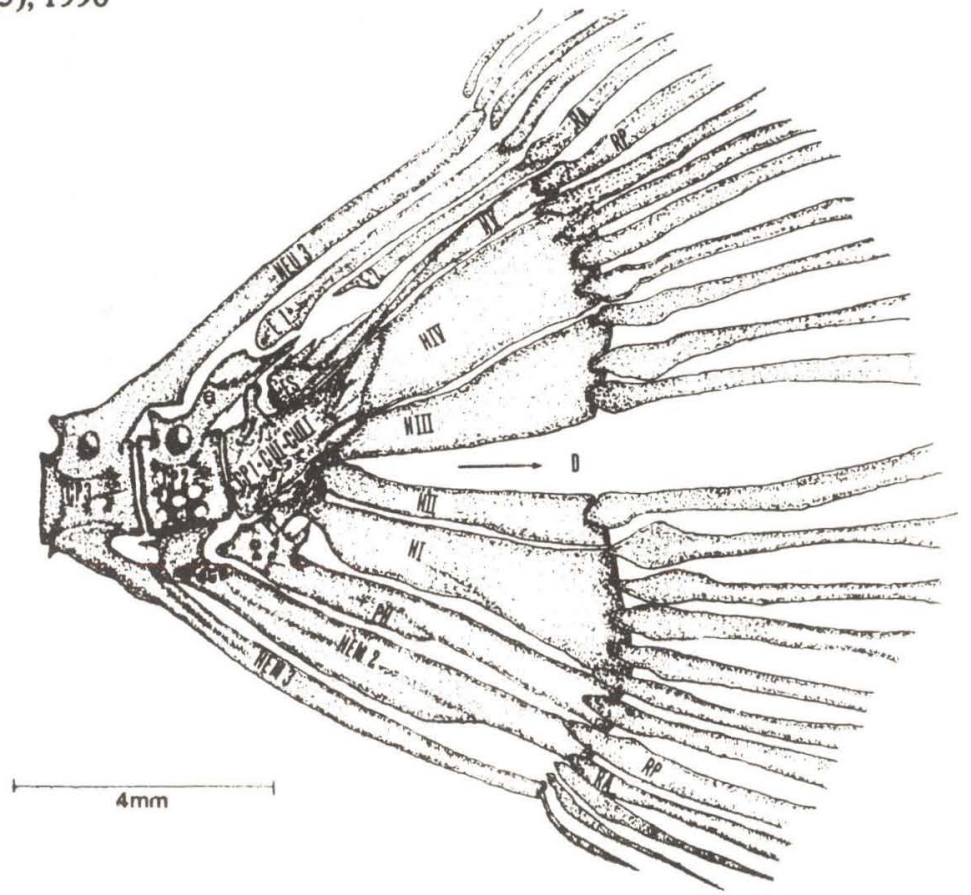

Fig. 4 - The urophore complex of Geophagus brasiliensis (Quoy \& Gaimard, 1824), lateral view.

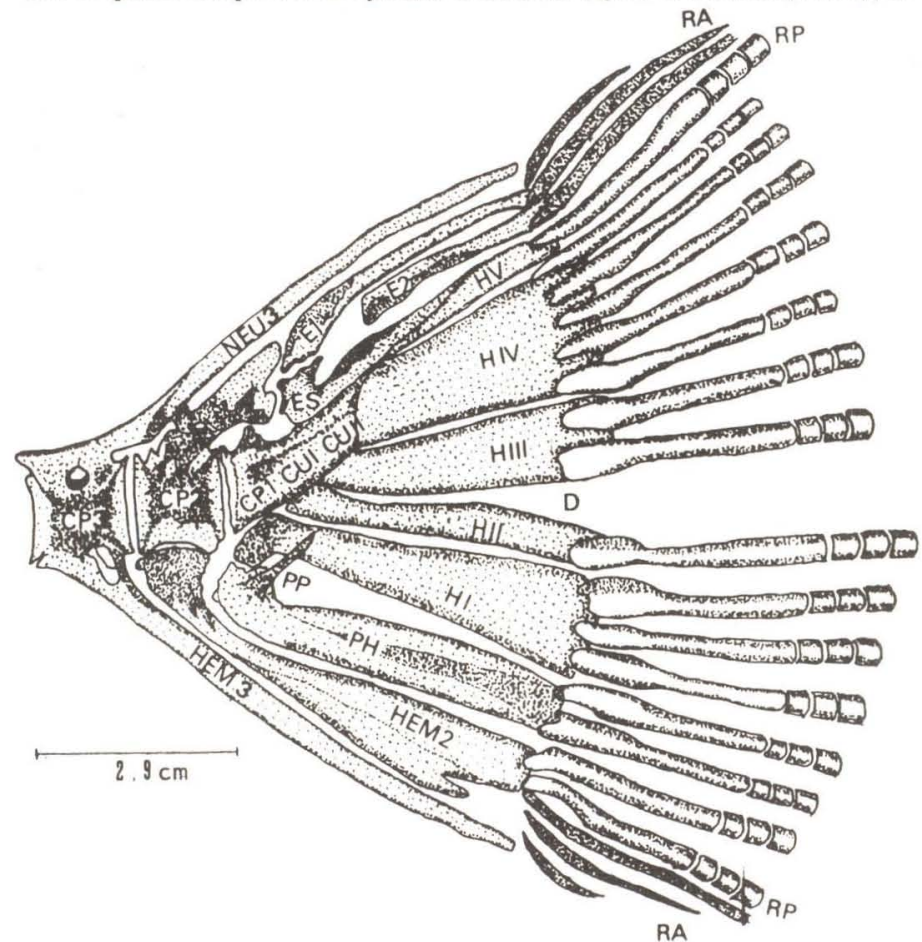

Fig. 5 - The urophore complex of Gymnogeophagus rhabdotus (Hensel, 1870), lateral view. 
Revta bras. Zool.

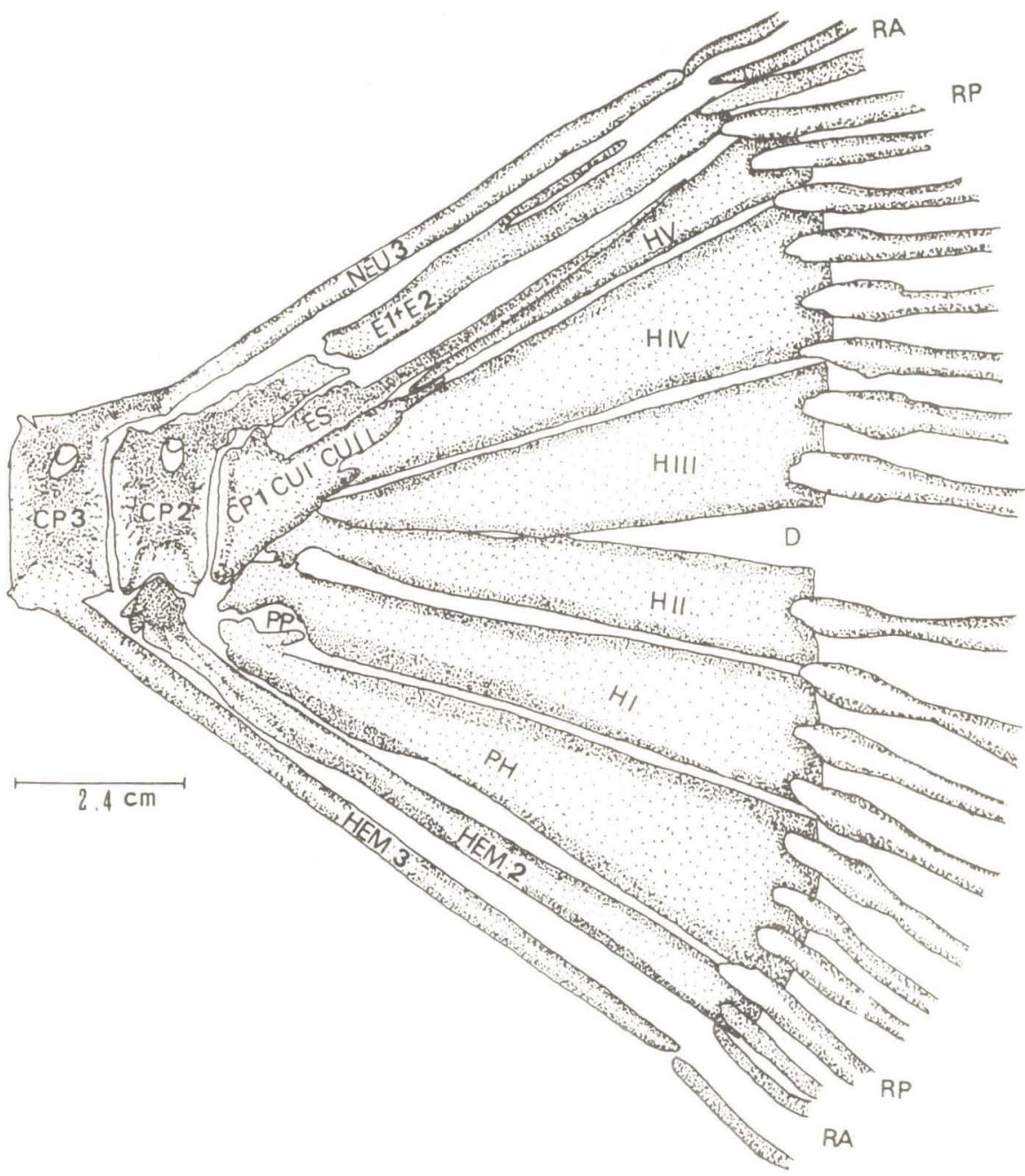

Fig. 6 - The urophore complex of Astronotus ocellatus (Swainson, 1839), lateral view. 
Vol. 7(3); 1990

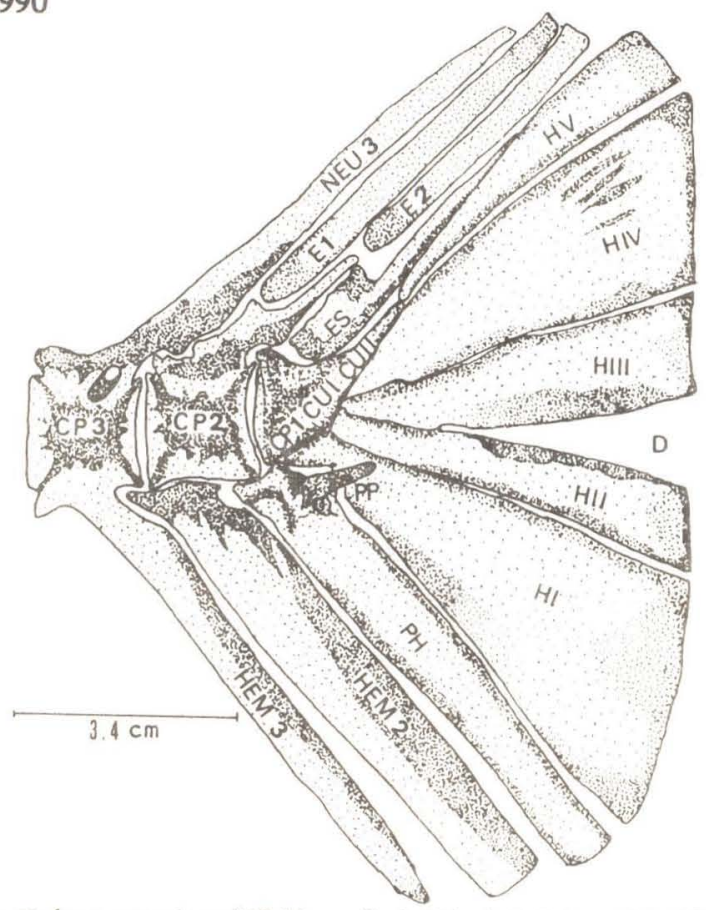

Fig. 7 - The urophore complex of Cichla ocellaris (Bloch \& Scheneider, 1801), lateral view.

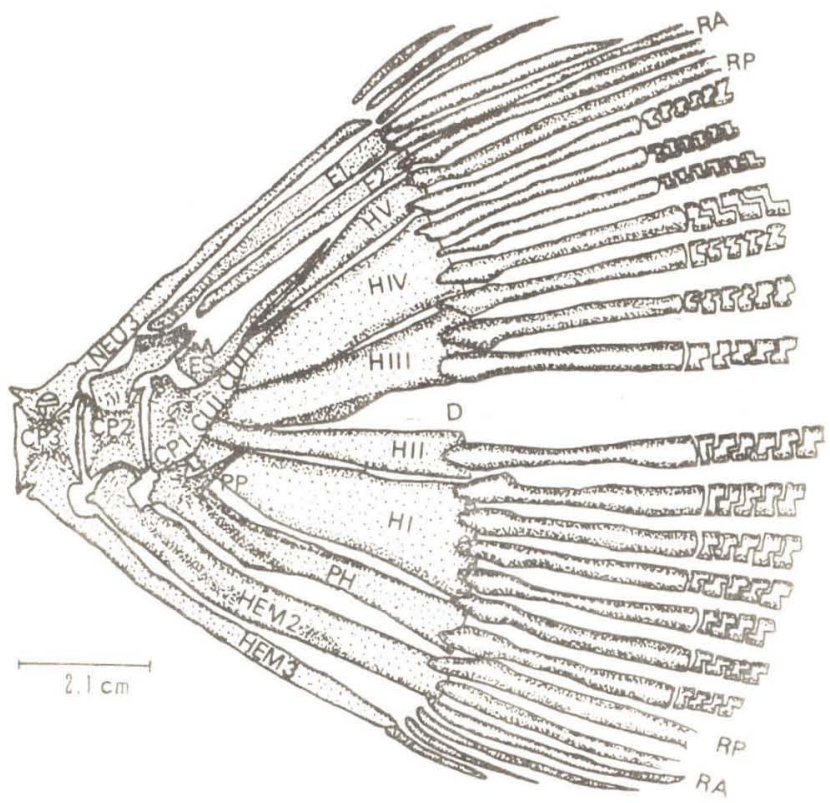

Fig. 8 - The urophore complex of Oriochromis niloticus (Linnaeus, 1758), lateral view. 
Revta bras. Zool.

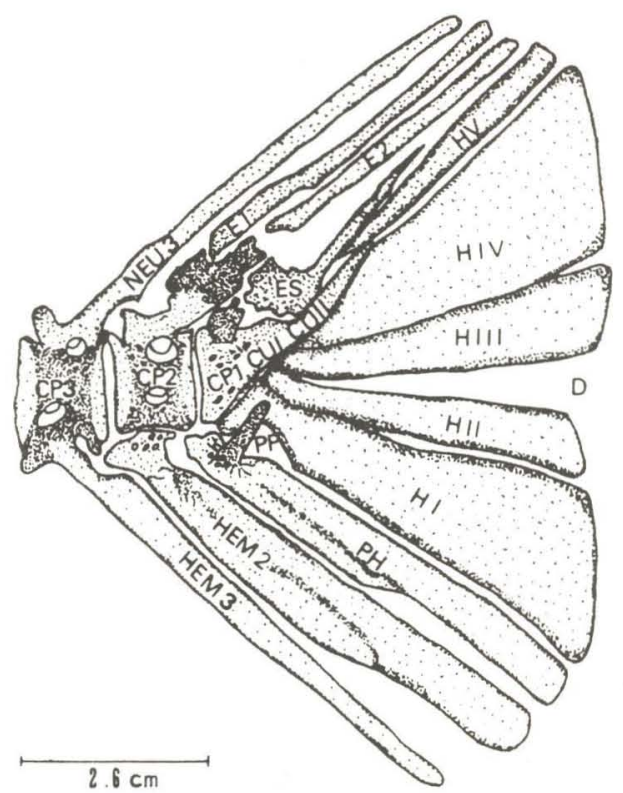

Fig. 9 - The urophore cemplex of Tilapia rendalli (Boulenger, 1898), lateral view.

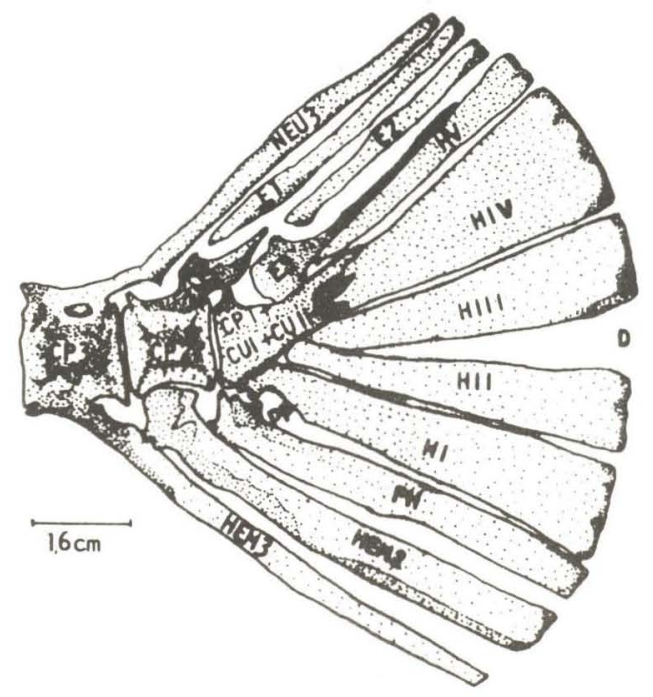

Fig. 10 - The urophore complex of Crenicichla lacustris (Castelnau, 1855), lateral view. 
Vol. 7(3), 1990

Table 1 - Caudal fin of some cichlids and their variation.

\begin{tabular}{|c|c|c|c|c|c|c|c|c|c|c|c|c|c|c|c|}
\hline SPECIES/CHARACTER & 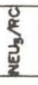 & 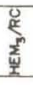 & $\begin{array}{l}8 \\
\end{array}$ & \& & \begin{tabular}{l}
0 \\
\multirow{2}{*}{} \\
\multirow{2}{*}{}
\end{tabular} & 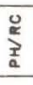 & $\stackrel{\mathscr{\alpha}}{\vec{x}}$ & $\stackrel{\mathscr{E}}{\underline{\underline{x}}}$ & 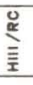 & $\frac{\mathscr{\alpha}}{\underline{z}}$ & $\frac{0}{\underline{\alpha}}$ & $\stackrel{a}{a}$ & $\dddot{2}$ & $\propto$ & $\stackrel{a}{\alpha}$ \\
\hline $\begin{array}{l}\text { Gymnogeophagus } \\
\text { chabdotus }\end{array}$ & 0 & 0 & 2 & 2 & 1 & 2 & 3 & 1 & 2 & 5 & 1 & HI & $22-23$ & 6-7 & 16 \\
\hline $\begin{array}{l}\text { Astronotus } \\
\text { pcellatus }\end{array}$ & 1 & 1 & 2 & 1 & 1 & 3 & 2 & 2 & 2 & 4 & 1 & $\mathrm{RD}$ & $22-23$ & $6-7$ & 16 \\
\hline $\begin{array}{l}\text { Crenicichla } \\
\text { lacustris }\end{array}$ & 1 & 1 & 2 & 2 & 1 & 2 & 3 & 2 & 2 & 4 & 2 & $\mathrm{RD}$ & 24 & 8 & 16 \\
\hline Crichlasoma facetum & 1 & 2 & 2 & 1 & 2 & 2 & 3 & 2 & 2 & 4 & 2 & HI & 23 & 7 & 16 \\
\hline $\begin{array}{l}\text { Cichlasoma } \\
\text { portalegrense }\end{array}$ & 0 & 1 & 2 & 1 & 1 & 2 & 3 & 2 & 2 & 5 & 1 & $\mathrm{RD}$ & 22 & 6 & 16 \\
\hline Cichla ocelaris & 3 & 3 & 2 & 2 & 1 & 2 & 4 & 2 & 2 & 4 & 2 & HII & $33-34$ & $17-18$ & 16 \\
\hline $\begin{array}{l}\text { Geophagus } \\
\text { prasiliensis }\end{array}$ & 2 & 2 & 2 & 1 & 1 & 2 & 4 & 1 & 2 & 4 & 1 & HI & 25 & 9 & 16 \\
\hline $\begin{array}{l}\text { preochromis } \\
\text { piloticus }\end{array}$ & 2 & 2 & 2 & 3 & 1 & 2 & 4 & 1 & 3 & 3 & 2 & HII & 25 & 9 & 16 \\
\hline Filapia rendalli & 2 & 2 & 2 & 2 & 1 & 2 & 4 & 1 & 2 & 4 & 2 & HII & 28 & 12 & 16 \\
\hline
\end{tabular}

\section{GENERIC DIFFERENTIATION}

The material studied disclosed differences regarding the caudal fin as can be shown by figure 1 and table I. The figure 1 was based and modified on Monod's models and has the purpose to define the general plan of the caudal fin of the cichilids under study. The urostyle, normally of a conical shape, can present a well pointed distal region as in Cichla ocellaris, Tilapia rendalli, Oreochromis niloticus, Geophagus brasiliensis and Crenicichla lacustris; or less marked, not pointed (reduced) as in Cichlasoma facetum, Cichlasoma portalegrense, Gymnogeophagus rhabdotus and Astronotus ocellatus. The neural spine of the pre-ural centrum 3 may not support any epaxial ray as in Gymnogeophagus rhabdotus and Cichlasoma portalegrense; supports one epaxial ray in Cichlasoma facetum, Astronotus ocellatus and Crenicichla lacustris; two epaxial rays in Tilapia rendalli, Oreochromis, niloticus and Geophagus brasiliensis, and can support three epaxial rays as in Cichla occelaris. Associated to the epurals, we may notice two epaxial rays as in Geophagus brasiliensis, Astronotus occelatus and Cichlasoma portalegrense; three epaxial rays in Tilapia rendalli, Cichla ocellaris, Gymnogeophagus rhabdotus, Crenicichla lacustris and Cichlasoma facetum, or even four epaxials rays as in Oreochromis niloticus. 
The parahypural and the haemal spine 2 present themselves in two different ways: they may undergo a progressive enlargement in relation to the distal region, as in Cichlasoma facetum, Gymnogeophagus rhabdotus; such enlargement being much more accentuated in Astronotus ocellatus; or they may undergo a progressive enlargement but the occurrence of a weak strangulation towards the medium-distal region as in Tilapia rendalli, Oreochromis niloticus, Geophagus brasiliensis, Cichla ocellaris and Crenicichla lacustris. In Cichlasoma portalegrense, the haemal spine 2 shows no strangulation while parahypural shows a smooth strangulation. The parahypural supports two hipaxial caudal rays in Tilapia rendalli, Oreochromis niloticus, Cichla ocellaris, Geophagus brasiliensis, Cichlasoma facetum and Cichlasoma portalegrense or even, can support three hipaxial rays as in Astronotus ocellatus. Associated to the epural 1, there may be one caudal ray in Geophagus brasiliensis, Astronotus ocellatus, Cichlasoma portalegrense and Cichlasoma facetum; two rays in Tilapia rendalli, Gymnogeophagus rhabdotus, Cichla ocellaris and Crenicichla lacustris, or three rays in Oreochromis niloticus. In Cichlasoma facetum, the epural 2 bears two caudal rays while in the other species only one caudal can be observed in association with this structure. The fifth hypural may support one caudal ray in Geophagus brasiliensis, Gymnogeophagus rhabdotus, Cichlasoma portalegrense and Astronotus ocellatus or two rays as in Tilapia rendalli, Oreochromis niloticus, Cichla ocellaris, Crenicichla lacustris and Cichlasoma facetum. Resting on the fourth hypural, three rays can be found in Oreochromis niloticus; four rays in Tilapia rendalli, Geophagus brasiliensis, Astronotus ocellatus, Crenicichla lacustris and Cichlasoma facetum or even five rays, in Gymnogeophagus rhabdotus and Cichlasoma portalegrense. In Oreochromis niloticus, the third hypural supports three caudal rays, whereas only two rays appears in the remaining species associated with this structure. The second hipural presents one caudal ray in Tilapia rendalli, Oreochromis niloticus, and in Gymogeophagus rhabdotus; or two rays as in the others species in this study. The first hypural bears two caudal rays in Astronotus ocellatus; three rays in Gymnogeophagus rhabdotus, Cichlasoma portalegrense, Cichlasoma facetum and in Crenicichla lacustris or four rays as in Cichla ocellaris, Tilapia rendalli, Oreochromis niloticus and Geophagus brasiliensis. In Cichlasoma portalegrense the total number of caudal rays are 22; in Gymnogeophagus rhabdotus and Astronotus ocellatus it varies from 22 to 23 rays; 23 rays in Cichlasoma facetum; 24 rays in Crenicichla lacustris; 25 reays in Oreochromis niloticus and Geophagus brasiliensis; 28 rays in Tilapia rendalli and 33 to 34 rays in Cichla ocellaris.

\section{GENERAL DISCUSSION AND CONCLUSION}

The evolution of the caudal fin in Teleosts began through a progressive simplification, with the loss or fusion of numerous independent bones (Gosline, 1961), mainly the hypurals that tend to group themselves, first in a double plate and then in a unique plate; this tendency is observed in some cichlids of the great African lakes (Vandewalle, 1973).

Rosen and Patterson (1969) proposed a primitive type of caudal fin of the Perciformes, showing 17 principal caudal rays, instead of 18 or 19 of primitive teleosts; three epurals; one pair of uroneurals; five hypurals; a pre-ural centrum 2 without neural spine; the fusion of $\mathrm{CP} 1+\mathrm{CUI}+\mathrm{CUII}$ to form the urostyle or urostylar ossification and, more anterior apaxials and hypaxials caudal rays as a true lepidotrichia. According to Patterson (1968), the cichlids differ from the basic type of Perciformes only for the loss or for 
the incorporation (by fusion) of the uroneural 2 into the stegural, and for the presence of the haemal arcs or spine of the pre-ural centra 3 and 2 autogenous (not blended). According to what we have observed on the cichlids under analysis, only the second haemal spine is autogenous whereas the haemal spine 3 is blended to its correspondent vertebral centrum thus differing from the basic type proposed by Patterson (op. cit.).

Vandewalle (1973), proposes a scheme showing the evolution of the caudal fin of the cichlids, where he analyzes several South American species and specially the African ones. This scheme does not take into account the kinship between the different genera, or the African and the South-American species; he analyzes, on a basis of likeness, only the evolution of the caudal fin but not the evolution of the group as a whole.

According to Pellegrin (1903), the cichlids descend from marine ancestors, probably the Pomacentridae, being considered, nowadays, as freshwater species although we have found perfctly adapted Tilapia rendalli and Geophagus brasiliensis in, estuarine environments (Tijuca and Marapendi Lagoons, Rio de Janeiro). Kaufman and Liem (1982) confirmed the origin of the Cichlidae as issued from the Pomacentridae, removing them from the suborder Percoidei and Pomacentroidei respectively, placing them with the Labridae and Embiotocidae in to the suborder Labroidei.

In our analysis of the caudal fin of the studied species, we verified that the Cichlidae present the osteological characteristics which permit their inclusion among the Perciformes "sensu stricto". This condition is represented by the presence of sixteen principal caudal rays; the presence of a true urostyle formed by the fusion of the pre-ural centrum 1 with the ural centra I and II; the presence of five hypurals and two epurals; the presence of a stegural and a pre-ural centrum 2 without neural spine but with a neural arch.

According to kullander (personnal comunication) "they are not most particularly interesting in regard to caudal fin, but cranial features will eventually lead to a better understanding of intrageneric relationships as species coverage becomes more complete". In spite of this argument, we thought that the shape of the urostyle, the parahypural and the haemal spine 2; the degree of ossification of the hypuraphophysis; the total number of caudal fin rays as well as their distribution on the elements supporting them would can be used as a characteristics of real taxonomic value. He has demonstrated that "some material countersained with alcian blue to show cartilage, and found that cartilage plate between hypurals 2 on 3, reported as an apomorphy for Cichla by Stiassny, seems to be more widespread, present also in Geophagus "sensu stricto" and Biodotoma; and as a rudiment (or possibly aberrant) in an Aequidens and Crenicichla species. It would seem to be plesiomorphic within cichlids, but perhaps in apomorphic for the family among percoids. The presence of a hypuraphophysis appears ancestral and is reduced to a various degrees in fishes with shortned caudal peduncle and in crenicichlines. The highest number of procurrent caudal rays is, too, ancestral, but reduced in a different lineages".

In fact, we does not repport the presence of this cartilage plate probably because our method was not specifit to repport this structure and it was destroyed by the method.

In our point of view, the caudal fin elements would provide characters for taxonomics and, perhaps phylogenetics approaches whem they are combined with cranial, myological and, in fact, the morphometricals and meristics, and it's very important took it in mind for later works in brazilian cichlids. 


\section{ACKNOWLEDGEMENTS}

We want to express our thanks to Dr. F.J. Meunier, Laboratoire d'Anatomie Compareè, Université Paris VII, for reading the manuscript and for valuable coments, and to

Prof. Philip C. Scott, Universidade Santa Úrsula, Rio de Janeiro, for reviewing the manuscript.

\section{REFERENCES}

ANDREATA, J.V., 1979. Osteologia da Nadadeira Caudal de Diapterus Ranzani e Eucinostomus Baird \& Girard (Perciformes-Percoidei-Gerridae). Rev. Brasil. Biol., 39 (1): 237-258.

DAVIS, D.D. \& U.R. GORE, 1936. - Clearing and staining skeletons of small vertebrates. Fid. Mus. Nat. Hist. Tech, 4:1-15.

GOSLINE, W.A., 1961. The perciform caudal skeleton. Copeia, 3: 265-270.

KAUFMAN, L.S. \& K.F. LIEM, 1982. Fishes of the Soborder Labroidei (Pisces: Perciformes): Phylogeny, Ecology and Evolutionary significance. Breviora, 472:1-19.

KULlANDER, S.O., 1981. A Cichlid from Patagonia. Buntbarsche Bull. J. Am. Cichl. Assn., 85: 13-23.

LOWE-McCONNEL, R.H., 1975. Fish communities on tropical freshwaters: Their distribution, ecology and evolution. Longman Inc. London and New York, 337 p.

MONOD, T., 1968. Le complexe urophore des poissons téléostéens. Mém. Inst. Fondam. Afrique Noire, 81:1-705.

PELLEGRIN, J., 1903. Contribution à l'étude anatomique, biologique, et taxonomique des Poissons de la famille des Cichlidés. Mém. Soc. Zool. France, 16:41-399.

PATTERSON, C., 1968. The caudal skeleton in mesozoic A canthopterygian fishes. Bull. Br. Mus. Nat. Hist., Geology, 17 (2): 49-102.

ROSEN, D.E. \& C. PATTERSON, 1969. The structure and relationship of Paracanthopterygian Fishes. Bull. Am. Mus. Nat. Hist., 141:359-474.

VANDEWALLE, P., 1973. Ostéologie caudale des Cichlidae. Bull. Biol., CVII : 275-289. 